\title{
Original
}

\section{Pancreatic Dysfunction and Imaging Abnormalities in Patients with Inflammatory Bowel Disease}

\author{
Junichi Nishikawa, Fumihiko Nozu, Ken Satoyoshi, \\ Masashi SaKamoto, Akifumi Ikegami, Yasushi Akita, \\ Nozomi Yoshikawa and Keiji Mitamura
}

\begin{abstract}
Background: Although patients with inflammatory bowel disease (IBD) frequently exhibit various extraintestinal manifestations, pancreatic disorder is not generally considered as an extraintestinal complication of IBD. We investigated pancreatic dysfunction and imaging abnormalities in patients with IBD. We estimated serum and urinary pancreatic enzyme levels for evaluation of pancreatic function in 42 patients with IBD, including 29 patients with ulcerative colitis (UC) and 13 patients with Crohn's disease (CD). In addition, some of the patients were examined by ultrasonography, abdominal computed tomography, and endoscopic retrograde pancreatography (ERP) for evaluation of pancreatic imaging. Elevation of serum or urinary pancreatic enzyme concentrations was observed in $23.8 \%$ of patients, and abnormal pancreatic imaging, in $26.7 \%$. In 4 patients, the pancreatic enzyme concentrations decreased or normalized during remission of IBD. In one patient initial ERP showed irregularity of the main pancreatic duct, and follow-up ERP indicated normal appearances of the duct after remission of IBD. Our observations suggest that pancreatic dysfunction and imaging abnormalities develop in patients with IBD; moreover, these may relate to the activity of disease and resolve when colonic inflammation is brought into remission.
\end{abstract}

Key words : inflammatory bowel disease, pancreatic disorder

\section{Introduction}

Various pancreatic manifestations of inflammatory bowel disease (IBD) and a number of pancreatic insufficiencies with IBD have been described since initial report of Ball et al. ${ }^{1}$.

However, pancreatic disorder is not yet widely considered as an extraintestinal manifestation of IBD. We investigated pancreatic dysfunction and pancreatic imaging abnormalities in patients with IBD.

\section{Methods}

Forty-two patients with IBD admitted to our hospital were studied. Twenty-nine patients, 
Table 1. Frequency of pancreatic dysfunction and image abnormalities with inflammatory bowel disease

\begin{tabular}{lccc}
\hline & UC & CD & Total \\
\hline $\begin{array}{l}\text { Elevation of } \\
\text { pancreatic enzymes }\end{array}$ & $20.7 \%(6 / 29)$ & $30.8 \%(3 / 13)$ & $23.8 \%(10 / 42)$ \\
\hline \hline Serum amylase & $10.6 \%(3 / 29)$ & $23.1 \%(3 / 13)$ & $14.3 \%(6 / 42)$ \\
Urine amylase & $13.8 \%(3 / 29)$ & $30.8 \%(4 / 13)$ & $19.0 \%(8 / 42)$ \\
Lipase & $13.8 \%(4 / 29)$ & $15.4 \%(2 / 13)$ & $14.3 \%(6 / 42)$ \\
Elastase 1 & $13.8 \%(4 / 29)$ & $15.4 \%(2 / 13)$ & $14.3 \%(6 / 42)$ \\
\hline $\begin{array}{l}\text { Abnormalities of } \\
\text { pancreatic imaging }\end{array}$ & $33.3 \%(6 / 18)$ & $16.7 \%(2 / 12)$ & $26.7 \%(8 / 30)$ \\
\hline $\begin{array}{l}\text { UC : ulcerative colitis } \\
\text { CD : Crohn's disease } \\
\text { performance of pancreatic enzyme examination : all cases } \\
\text { performance of pancreatic imaging examination : UC-18 cases, CD-12 cases }\end{array}$
\end{tabular}

16 males and 13 females, with ulcerative colitis (UC) had a mean age of 35.0 (range 1377). The extent of their disease was determined by barium enema or complete colonoscopy.

UC involved the entire colon in 18 patients, the left colon in 9, and the rectum in 2 . Thirteen patients, 8 males and 5 females, with Crohn's disease (CD) had a mean age of 37.2 (range 21-53). Both the small intestine and the colon were involved in 5 patients, and the colon alone in 8 patients. We performed serum and urinary pancreatic enzyme examinations for all patients, abdominal ultrasonography (US) for 30, abdominal computed tomography scans (CT) for 13, and endoscopic retrograde pancreatography (ERP) for 16 patients. Evaluation of imaging abnormalities was based on criteria proposed by the International Workshop at Cambridge ${ }^{2)}$. We obtained informed consent for the study of pancreatic disorder from all patients.

\section{Results}

Elevations of serum or urine amylase, lipase, and elastase I values were observed in 10 (23.8\%) out of 42 patients with IBD, including 6 patients with UC $(20.7 \%)$ and 4 patients with CD $(30.8 \%)$ (Table 1$)$. Elevated amylase concentrations in serum or urine included the pancreatic type isoenzyme.

Pancreatic imaging showed chronic pancreatitis in $8(26.7 \%)$ out of 30 patients examined, including 6 with UC (33.3\%) and 2 with CD (16.7\%) (Table 1). All pancreatic imaging abnormalities on US or CT were detected by ERP. ERP was particularly useful (Table 2). In all patients diagnosed by ERP, as having pancreatic duct abnormalities, mild or moderate pancreatitis was confirmed.

Combining biochemical tests and imaging examinations, 14 patients had pancreatic dysfunction or imaging abnormalities (Tables 3 and 4). Pancreatic disorder was not associated with age or sex, and there was no relationship between pancreatic enzyme concentrations and severity of imaging abnormalities. In 4 patients pancreatic imaging examinations showed chronic pancreatitis despite normal enzyme concentrations, and 4 patients with normal pancreatic imaging revealed elevation of pancreatic enzyme concentrations. Pancreatic disorder was often observed in patients with UC involving the entire 
Table 2. Frequency of abnormality on pancreatice imaging in patients with inflammatory bowel disease

\begin{tabular}{lrrr}
\hline & UC & \multicolumn{1}{c}{ CD } & \multicolumn{1}{c}{ Total } \\
\hline \hline US & $5.6 \%(1 / 18)$ & $8.3 \%(1 / 12)$ & $6.7 \%(2 / 30)$ \\
CT & $0 \%(0 / 7)$ & $16.7 \%(1 / 6)$ & $7.7 \%(1 / 13)$ \\
ERP & $54.5 \%(6 / 11)$ & $40 \%(2 / 5)$ & $50.0 \%(8 / 16)$ \\
\hline
\end{tabular}

UC : ulcerative colitis

CD : Crohn's disease

US : ultrasonography

CT : computed tomography

ERP : endoscopic retrograde pancreatography

Table 3. Pancreatic dysfunction and imaging abnormalities in patients with uncerative colitis

\begin{tabular}{|c|c|c|c|c|c|c|c|c|c|}
\hline case, age, sex & 1.44, M & 2.39, M & $3.63, \mathrm{~F}$ & $4.77, \mathrm{~F}$ & $5.42, \mathrm{~F}$ & $6.65, \mathrm{M}$ & 7.37, $\mathbf{M}$ & $8.38, \mathrm{M}$ & $9.20, \mathrm{M}$ \\
\hline type & Total & Left-C & Total & Total & Total & Left-C & Total & Left-C & Left-C \\
\hline severity of disease & moderate & mild & mild & severe & moderate & moderate & severe & severe & mild \\
\hline therapy for UC & SASP, PSL & SASP & PSL & SASP & SASP & $\begin{array}{l}\text { SASP, } \\
\text { PSL }\end{array}$ & SASP & $\begin{array}{l}\text { SASP, } \\
\text { PSL }\end{array}$ & SASP \\
\hline alcohol intake & $(-)$ & $(-)$ & $(-)$ & $(-)$ & $(-)$ & $(+)$ & $(+)$ & $(+)$ & $(+)$ \\
\hline cholelithiasis & $(-)$ & $(-)$ & $(-)$ & $(-)$ & $(+)$ & $(-)$ & $(-)$ & $(-)$ & $(-)$ \\
\hline $\begin{array}{l}\text { symptoms of } \\
\text { pancreatitis }\end{array}$ & $(-)$ & $(-)$ & $(-)$ & $(-)$ & $(-)$ & $(-)$ & $(-)$ & $(-)$ & $(-)$ \\
\hline duration of disease & $1 \mathrm{M}$ & $30 \mathrm{M}$ & $1 \mathrm{M}$ & $2.5 \mathrm{M}$ & $1 \mathrm{M}$ & $18 \mathrm{M}$ & $1 \mathrm{M}$ & $60 \mathrm{M}$ & $7 \mathrm{w}$ \\
\hline $\begin{array}{l}\max \text { S-Amylase } \\
(\text { isozyme })(\mathrm{IU} / \mathrm{I})\end{array}$ & $823(\mathbf{P}) \uparrow$ & 85 & 220 & $355(\mathbf{P}) \uparrow$ & 127 & 92 & $279(\mathbf{P}) \uparrow$ & 183 & 122 \\
\hline $\begin{array}{l}\max U \text {-Amylase } \\
(\text { isozyme })(\mathrm{IU} / \mathbf{I})\end{array}$ & $6924(\mathrm{P}) \uparrow$ & 430 & $\mathrm{nt}$ & nt & nt & nt & $902 \uparrow$ & $950(\mathbf{P}) \uparrow$ & $1269 \uparrow$ \\
\hline $\max \operatorname{Lipase}(\mathrm{IU} / \mathrm{I})$ & $3093 \uparrow$ & 54 & $359 \uparrow$ & $801 \uparrow$ & 81 & 100 & $287 \uparrow$ & 193 & nt \\
\hline $\max$ Elastase-1 (ng/dl $)$ & $3267 \uparrow$ & 161 & $523 \uparrow$ & $693 \uparrow$ & nt & 289 & $1182 \uparrow$ & nt & nt \\
\hline $\begin{array}{l}\text { exocrine function } \\
\text { (PS test, PFD) }\end{array}$ & $\begin{array}{l}\text { mild } \\
\text { dysfunction }\end{array}$ & nt & nt & nt & nt & nt & nt & nt & nt \\
\hline abdominal US & $\begin{array}{l}\text { chronic } \\
\text { pancreatits }\end{array}$ & normal & normal & normal & normal & normal & normal & normal & normal \\
\hline abdominal CT & normal & nt & normal & nt & normal & nt & normal & normal & normal \\
\hline ERP & MIP & MIP & MIP & MIP & MIP & MIP & normal & normal & nt \\
\hline
\end{tabular}

Total : total colitis Left-C : left-sided colitis SASP : salazosulfapyridine PSL : prednisolone

MIP : mild pancreatitis MOP : moderate pancreatitis nt: not tested

colon or the left colon. Incidence of pancreatic dysfunction also increased in patients with CD involving both the small intestine and the colon; however, the incidence did not correlate with the activity of disease. 
Table 4. Pancreatic dysfunction and imaging abnormalities in patients with Crihn's disease

\begin{tabular}{|c|c|c|c|c|c|}
\hline case, age, sex & 10.35, M & $11.53, \mathrm{~F}$ & $12.28, \mathrm{M}$ & $13.38, \mathrm{M}$ & 14.25, M \\
\hline type & \multicolumn{2}{|c|}{ small int-colon colon } & \multicolumn{3}{|c|}{ small int-colon small int-colon small int-colon } \\
\hline severity of disease (IOIBD score) & 5 & 7 & 3 & 3 & 3 \\
\hline therapy for UC & $\begin{array}{l}\text { Metronidazole, } \\
\text { Tranilast }\end{array}$ & SASP & $(-)$ & SASP, PSL & SASP \\
\hline alcohol intake & $(+)$ & $(-)$ & $(-)$ & $(-)$ & $(-)$ \\
\hline cholelithiasis & $(-)$ & $(-)$ & $(-)$ & $(-)$ & $(-)$ \\
\hline duodenal lesion & $(-)$ & $(-)$ & $(-)$ & $(-)$ & $(-)$ \\
\hline symptoms of pancreatitis & $(-)$ & epigastric pain & $(-)$ & $(-)$ & $(-)$ \\
\hline duration of disease & $39 \mathrm{M}$ & $3 \mathbf{W}$ & $7 \mathbf{M}$ & $9 \mathrm{Y}$ & $6 \mathrm{M}$ \\
\hline $\max$ S-Amylase (isozyme) $(\mathrm{IU} / \mathrm{I})$ & 81 & $1927(\mathrm{P}) \uparrow$ & 139 & $290(\mathbf{P}) \uparrow$ & $288 \uparrow$ \\
\hline $\max$ U-Amylase (isozyme) $(\mathrm{IU} / \mathrm{I})$ & 159 & $12460(\mathbf{P}) \uparrow$ & $1357(\mathbf{P}) \uparrow$ & $2582(\mathrm{P}) \uparrow$ & $1236 \uparrow$ \\
\hline $\max \operatorname{Lipase}(\mathrm{IU} / \mathrm{I})$ & nt & $5360(\mathrm{P}) \uparrow$ & nt & $393(\mathbf{P}) \uparrow$ & 10 \\
\hline $\max$ Elastase-1 (ng/dl) & 140 & $3715(\mathbf{P}) \uparrow$ & nt & $763(P) \uparrow$ & nt \\
\hline exocrine function (PS test, PFD) & nt & $\begin{array}{l}\text { mild } \\
\text { dysfunction }\end{array}$ & nt & nt & nt \\
\hline abdominal US & normal & $\begin{array}{l}\text { chronic } \\
\text { pancreatitis }\end{array}$ & nt & normal & normal \\
\hline abdominal CT & normal & pancreatitis & nt & normal & normal \\
\hline ERP & MIP & MOP & nt & normal & normal \\
\hline
\end{tabular}

small int-colon : small intestine and colon type colon : colon type SASP : salazosulfapyridine IOIBD : International Organization for the Study of Inflammatory Bowel Disease

PSL : prednisolone nt: not tested MIP : mild pancreatitis MOP : moderate pancreatitis

None of 14 patients had pancreatic disorder due to drugs. Five patients were habitual ethanol drinkers, and one patient had a gallstone. No patient had a duodenal lesion observed in $\mathrm{CD}$, and none had a metabolic disease associated with pancreatic disorder.

In 4 of 10 patients with elevated pancreatic enzyme levels in the active phase of IBD, the elevated pancreatic enzyme concentrations decreased or normalized during remission of IBD (Cases 1, 4, 11, 14). Follow-up ERP was done on one patient (Case 11); she experienced epigastric pain and elevation of pancreatic enzyme concentrations in the active phase of CD.

Initial ERP performed in the active phase showed the irregular main pancreatic duct (MPD) ; however, follow-up ERP showed a normal appearance of the MPD after remission of IBD (Fig. 1).

\section{Discussion}

\section{Pancreatic disorder associated with UC}

Patients with UC occasionally manifest pancreatic disorder. Ball et al. ${ }^{1)}$ found interstitial pancreatitis in 46 of 86 autopsied cases of UC (53\%), and parenchymal fibrosis and atrophy in 11 cases. Chapin et al. ${ }^{3)}$ also reported that abnormal pancreatic histology was frequent in UC. Angelini et al. ${ }^{4)}$ reported that exocrine pancreatic dysfunction was found in $30 \%$ of patients with UC.

We evaluated that none of our subjects had drug-related etiologies or metabolic disease. 


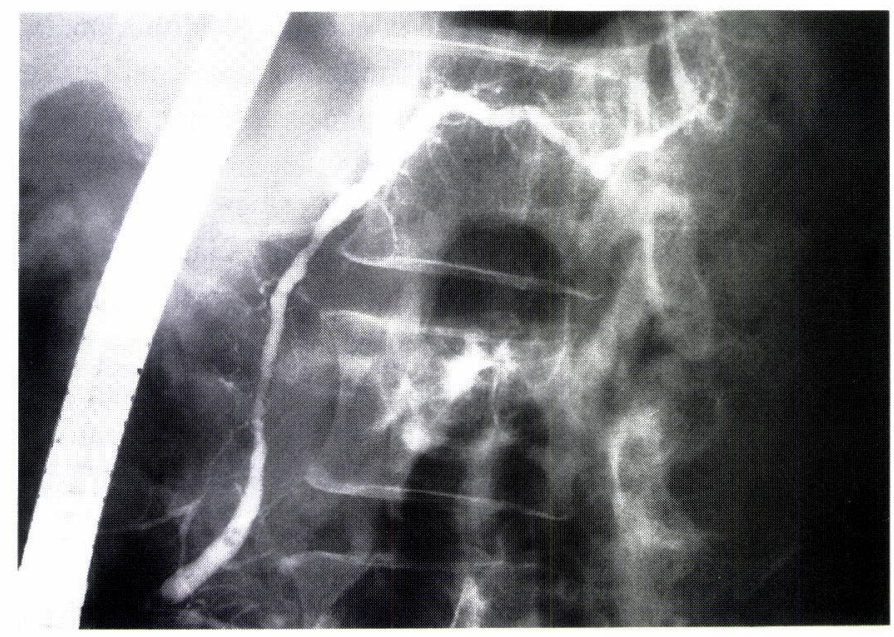

Fig. 1A, Initial ERP showed the irregular main pancreatic duct

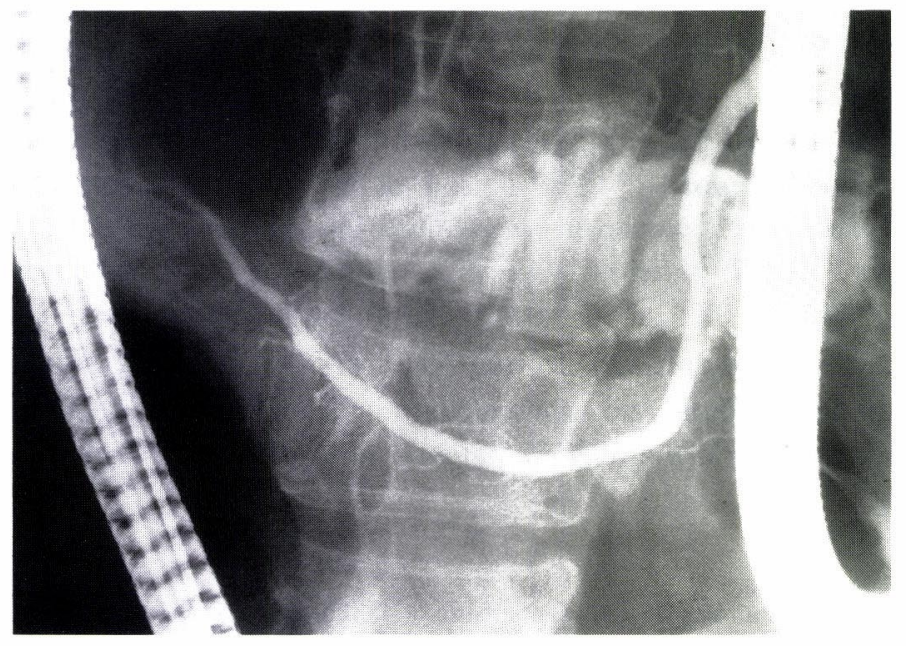

Fig. 1B, Follow-up ERP after remission of IBD showed normal appearance of the main pancreatic duct

Four of our patients were habitual ethanol drinkers. Only one had a gallstone. These conditions were not considered related to pancreatic disorder. We considered other well-known etiologies of pancreatic disorder.

Possible mechanisms of pancreatic disorder associated with UC include activation of trypsinogen by bacterial infection, nutritional compromise, and disordered microcirculation due to irritation of autonomic nerves ${ }^{5)}$. Other potential mechanisms include hyperamylasemia induced by stress via adrenal cortical hormones, irritation of the pancreatic parenchyma and interstitium by proteases and cytokines produced in the colonic mucosa, and increased viscosity of secretions arising by dehydration from intestinal motor paralysis ${ }^{6)}$. None of these hypotheses is favored over the others by the present study.

Two patients in our study revealed decreases or normalization of pancreatic enzyme levels 
after remission of UC. This result suggests that pancreatic dysfunction in patients with UC may relate to the activity of disease. Pancreatic imaging abnormalities, especially on ERP, were found in some patients with UC. However, pancreatic imaging abnormalities in our patients were minimal changes.

Pancreatic disorder associated with CD

There are several prior reports of pancreatic disorder associated with CD. Chapin et al. ${ }^{3)}$ reported that fibrosis of the interstitium or surrounding pancreatic ducts were seen in 15 of 39 autopsied patients. Seidman et al. ${ }^{7)}$ reported a case of pancreatitis in which inflammation of surrounding pancreatic ducts and interstitial fibrosis were seen in a pancreatectomy specimen. Dreiling ${ }^{8)}$ observed exocrine dysfunction in $18 \%$ of patients by the secretin test, and Angelini et al. $^{4)}$ found the same dysfunction in $35 \%$ of patients by secretin and caerulein tests.

In our study one patient was a habitual ethanol drinker. However, there were no other well-known etiologies of pancreatic disorder such as drug use, gallstones, or metabolic disease.

With regard to the mechanism of pancreatic disorder in patients with $\mathrm{CD}$, Altman et al. ${ }^{\text {) }}$ reported that a reflux of duodenal contents into the pancreatic duct had been proved in cases of CD having a duodenal lesion. Recently, a case of duodenal Crohn's disease involving the ampulla of $\operatorname{Vater}^{10)}$ and a case showing histologically granulomatous inflammation consistent with Crohn's disease involving the stomach, duodenum, and head of the pancreas ${ }^{11)}$ have been reported. The notion of reflux or mechanical obstruction of the pancreatic duct is attractive; however, we found no patient with CD having duodenal lesions in our study. In 2 patients with $C D$, similar to UC, pancreatic enzyme levels improved with remission of CD in our study. ERP was performed for one patient with CD in both active and inactive phases. Initial ERP showed chronic moderate pancreatitis; however, follow-up ERP found no abnormality. Therefore, we assume that pancreatic dysfunction and imaging abnormalities in patients with IBD may relate to the activity of disease.

\section{References}

1) Ball WP, Baggentoss AH and Bargen JA: Pancreatic lesion associated with chronic ulcerative colitis. Arch Pathol Lab Med, 50 : 345-358 (1950)

2) Sarner $M$ and Cotton PB : Classification of pancreatitis. Gut, 25 : 756-759 (1984)

3) Chapin LE, Scudamore HH, Baggenstoss AH and Bargen JA : Regional enteritis : associated visceral changes. Gastroenterology, 30 : 404-415 (1956)

4) Angelini G, Gavallini G, Bovo P, Brocco G, Castagnini A, Lavarini E, Merigo F, Tallon N and Scuro LA : Pancreatic function in chronic inflammatory bowel disease. Int $J$ Pancreatol, 3 : 185-193 (1988)

5) Muraoka M, Aiso S, Miura S, Tanaka Y, Hokudou T, Mizuno Y, Asakura H, Tsuchiya M, Hibi N, Suzuki J, Yokota A and Utsunomiya T : Examination of extra-intestinal complication with ulcerative colitis. Nippon Shokakibyo Gakkai Zasshi, 75 : 1727-1733 (1978)

6) Sugita A, Fukushima T, Takemura $\mathrm{H}$ and Tsuchiya $\mathrm{S}$ : Hyperamylasemia in ulcerative colitis. Nippon Shokakibyo Gakkai Zasshi, 79 : 1412-1417 (1982)

7) Seidman EG, Deckelbaum RJ, Owen H, de-Chadarevian JP, Wever AM, Morin CL and Roy CC: Relapsing pancreatitis in association with Crohn's disease. J Pediatr Gastroenterol Nutr, 2 : 178-182 (1983)

8) Dreiling DA : Studies of pancreatic function.V. The use of the secretion test in the diagnosis of pancreatitis and in the demonstration of pancreatic insufficiencies in gastrointestinal disorders. Gastroenterology, 24:540555 (1953)

9) Altman HS, Phillips G, Bank S and Klotz H: Pancreatitis associated with duodenal Crohn's disease. Am J Gastroenterol, 78 : 174-177 (1983)

10) Eisner TD, Goldman IS and McKinley MJ : Crohn's disease and pancreatitis. Am J Gastroenterol, 88 : 583-586 
(1993)

11) Gschwantler M, Kogelbauer G, Klose W, Bibus B, Tscholakoff D and Weiss W: The pancreas as a site of granulomatous inflammation in Crohn's disease. Gastroenterology, 108 : 1246-1249 (1995)

[Received March, 26, 1998 : Accepted May, 8, 1998] 